\title{
FACTORS INFLUENCING THE PURCHASING DECISIONS OF LOW EMISSION CARS: COMPARING STUDY BETWEEN EGYPT AND SLOVENIA
}

\author{
ALAA OTHMAN $^{1}$, AHMED DABEES ${ }^{1}$, BAHER RAHMA ${ }^{1}$, MATJAZ KNEZ ${ }^{2}$ \\ ${ }^{1}$ College of international Transport\& Logistics at Arab Academy for Science, Technology and \\ Maritime Transport, Alexandria, Egypt, Alaa.abomousa@gmail.com, \\ Ahmed_dabees@hotmail.com,baherrahma@gmail.com \\ ${ }^{2}$ University of Maribor, Faculty of Logistics, Slovenia, Matjaz.knez@um.si
}

\begin{abstract}
This paper provides a study about the factors influencing the purchasing of low emission vehicles. In order to achieve the objectives of the paper, and in the light of the pool of literature and availability of data, the authors relied on qualitative methods to offers a comparison between Egypt as a developing country and Slovenia as a developed country, through analysing a survey that involves an Egyptian sample and Slovenian samples, it also studies the effect of different push and pull methods on different buyers in order to help the governments as well as the manufacturers to understand the most significant factors that affects the purchasing behaviour of LEV in the future. The results of this paper show the important vehicle performance factors, financial considerations and Environmental considerations along with the gender and age of the consumer and show that consumers are more interested in the total price of the car than in different taxes.
\end{abstract}

Keywords: Low emission vehicles, purchasing behaviour, developed and developing countries

\section{INTRODUCTION}

Despite the contextual differences between developed and developing countries, there is an agreed opinion from researchers in both regions that the green technologies, especially in the area of green transport, are interesting for policy makers, vehicle producers, customers and energy suppliers. Many stakeholders from public and private sector are devoting a lot of effort to identify customer behaviour for future enhancements in development of their green products and strategies (El-Dorghamy, 2014; Knez et al., 2014). The predictions of the International Energy Agency (2017) estimate that world energy demand from 2005 to 2030 will increase by approximately $52 \%$, while forecast of World Energy Council estimate that energy demand will double by 2050, which is similar to IEA's prediction (Obrecht and Denac, 2011).

Environmental Performance Index (EPI) rankings ranks countries on how close they are to established environment policy goals and indicate how well governments are controlling or dealing with pollution against the range of environmental pressures that every country faces. The 2018 (EPI) ranks 180 countries on 24 performance indicators across ten issue categories covering environmental health and ecosystem vitality. This report declared that Slovenia currently ranks 34th rank while Egypt currently ranks 66th (EPI, 2018). The automotive sector in Egypt has a vital contribution in the Egyptian economic growth. It is consequently necessary to achieve a balance between the environmental and economic drives of policy makers in order to be assessed in terms of its environmental, economic, and social impact based on Cost-Benefit Analysis (CBA) that also take into consideration the external costs and external benefits together with the other common economic indicators (El-Dorghamy, 2014).

In Slovenia the issue of air pollution is largely high, linked especially to $\mathrm{PM}_{10}$ which are caused by road transport, especially in urban centres with heavy traffic in Ljubljana as well as emissions from heating appliances and industrial sources in Zasavje and Celje. Measurements of $\mathrm{PM}_{10}$ indicate an exceeding of the limit values across the whole of Slovenia, and especially in winter in the inner areas (Slovenian Environment Agency, 2019). 
Current energy import dependency in the EU and in Slovenia stands at approximately $50 \%$. Energy specialties have forecasted that the EU and Slovenia as a member state in it will change over to a sustainable energy industry by 2046, considering that there are no significant oil reserves, and they highly depending on importing oil which can lead to economic and socio-political risk.

Egypt is considerably the largest consumer of oil and natural gas in Africa, showing $22 \%$ of petroleum and other liquids of African total consumption and $37 \%$ of its dry natural gas consumption. Egypt face a low variety of oil importers as the major portion of the Egyptian imported oil ( 4.9 million tons), imports only from three suppliers: Kuwait, Iraq and Oman (Atlam and Rapiea, 2016). Minister of Environment Khaled Fahmy appeals that the government is working on reducing vehicle consumes by switching recent cars with low emission electric ones and he stated that 15 electric buses were put forward in Alexandria in 2018. Nevertheless, it would require charging stations, parking lots, and energy sources to supply the cars, but it would be more economical than gasoline in any other car, as well as there is a huge difference between the technology compared to their counterparts in gasoline (Awad, 2018). According to Director General of Brilliance-Bavarian auto group and Ellithy group company, the electric car has two methods of charging. First, is the (Home shipping) in which the Charging time lost by 220 volts' charger is from 2.30 hours 3.30 hours in case of battery $0 \%$. Second, is the "External freight points" or "shipping stations" which become "available" significantly in Cairo and the governorates of Egypt and desert roads. As well as, High-speed superchargers are installed nowadays to recharge the battery in 30 minutes to facilitate travel. In addition, it does not need maintenance like any other car as the electric motor does not need oils for cooling and does not have any belts or pouches or filters and does not produce any heat which is environmentally friendly.

\section{METHODOLOGY}

The study presented in this paper is a comparative research study. A comparative approach was chosen to investigate the similarities and differences in the factors influencing the purchasing of low emission decisions between developing and developed countries. For the developed country, Slovenia was selected as it is the green heart of Europe; it has abundant natural features placed between the Mediterranean, Central and Southeast Europe. In addition, Slovenia has achieved numerous development goals that helps in raising the level of economy, better outcomes in social and environmental improvement. For the developing country, Egypt has been selected as its one of the largest economies in the Arab world and home to one of the fastest growing middle classes in the Middle East and North Africa region. In additions, Egypt opened up new possibilities with more economic intelligent, social inclusive, environmental responsibility as well as with many challenges.

For the primary data collection, a pre-structured questionnaire was distributed in Slovenia then Egypt. We processed the collected empirical data by using SPSS 18. First, a descriptive statistical analysis was carried out for each of the two countries' samples. In the second step, significant differences in mean of vehicle performance factors, financial considerations and Environmental considerations along with the gender and age of the consumer between Egypt and Slovenia were investigated. We follow a sequential mixed methodology, with the qualitative phase following a descriptive phase. A mixed methods study combines both qualitative and quantitative analysis for the purpose of better understanding an issue, the survey targeted 1086 samples from Egypt and 681 samples from Slovenia whose current opinion about relevant vehicle performance aspects and financial factors for vehicle purchasing decisions was studied. 
In addition, secondary data was collected with compilation method from books, online references and periodicals and specialized journals in sustainability, various scientific and professional papers, researches and project reports focused on the research topic at hand.

\section{DISCUSSION OF RESULTS}

The study was designed to reveal the underlying factors that affect the purchasing habits of people. The results reveal new perspective of purchasers, and indicate which factors are the most important for the purchase of a LEV. Results display the important vehicle performance factors, financial considerations and Environmental considerations. Results also show the reasons beyond future decision to buy a lower emission car as well as the gender and age distribution between different segments of consumers. Bar charts are used to show different results.

Figure 1 displays the important vehicle performance factors with respect to males and females in Egypt versus Slovenia, it could be noted that Luggage/storage space is more important for women, while, Body shape (e.g. hatchback, saloon, estate), Mileage (if you buy a used car), Acceleration time, Fuel type, and Model of vehicle (e.g. Golf, Clio) are more important for men. However, in Slovenia, the results indicated that there are some differences between male and female population, especially when examining safety features, acceleration and fuel type. Safety is more important for women; acceleration and fuel type are more important for men. The interesting point shown is that women find safety more important than men, even though they cause much fewer traffic accidents. The Two non-financial factors are crucial when deciding on a car purchase - 1: "overall condition and mileage of vehicle (when buying a used car)", and - 2: "safety features", other very important factors are: vehicle size (exterior), style/appearance/colour, body shape (e.g. hatchback, coupe, etc.) and fuel type.
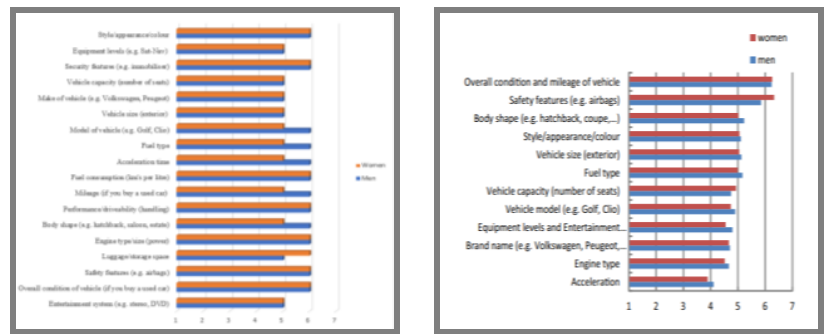

Figure 1. Important Vehicle Performance Factors in Egypt versus Slovenia

Figure 2 displays the important financial considerations with respect to males and females in Egypt versus Slovenia, it could be noted that Maintenance/repair costs, Insurance group for vehicle, and Annual road tax Fuel economy (How much fuel it uses per $\mathrm{km}$ ) are more important for women. On the other hand, in Slovenia, most important thing seems to be the total price of the vehicle. Second feature, also very important, is fuel economy. Especially now when gas prices are high and still increasing, information on fuel consumption is crucial. People also put emphasis on repair costs and on the value/money ratio. Two features that are less important are "trade-in value" (how much money you get when you sell your vehicle) and "annual road tax". 

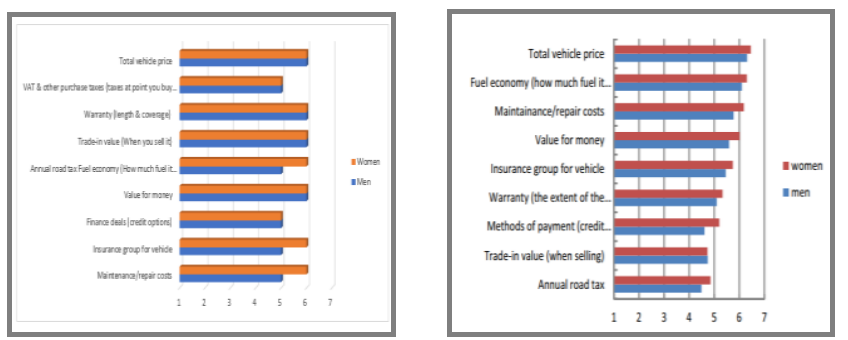

Figure 2. Important Financial Considerations

Figure 3 presents the important Environmental Considerations in Egypt and Slovenia. The results from Egypt indicate that there is no difference between Women and Men in Emissions of $\mathrm{CO}_{2}$ and other greenhouse gases. However, it could be noted that Emissions of other air pollutants, and Vehicle noise are more important for women. In Slovenia, they scored high grades on the question about $\mathrm{CO}_{2}$ and other emissions. Moreover, they are also very attentive about vehicle noise.

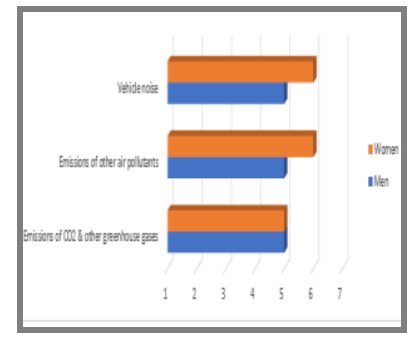

Figure 3. Important Environmental Considerations
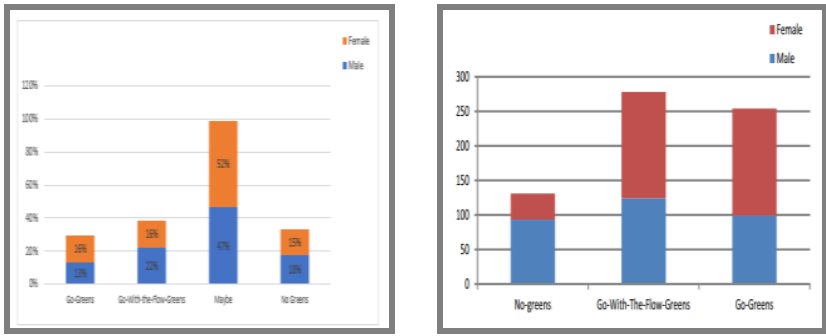

Figure 4. Ratio between Males and Females in different Consumers Segments

The results obtained for ratio between males and females in different segments of consumers. The Egyptians show that only $52 \%$ of all females are in the "Maybe" group, followed by both "Go-With-The-Flow-Greens" and "Go-Greens" as they got 16\%, and finally is "No Green" group as it got $15 \%$. For Male respondents, the highest group is the "Maybe", as it got 47\% followed by "Go-With-The-Flow-Greens" group with a percentage of $22 \%$, is the third place is "No Green" group with $18 \%$, finally, "No Green" group with only $13 \%$. While the Slovenians show that only $11 \%$ of all women are in the-No-green- group and the remaining $89 \%$ are a part of the other two groups. Men are more equally distributed through all three groups $(29.4 \%$ in No-Greens, $39.2 \%$ 
in the Go-With-The-Flow-Greens and 31.3\% in the Go-Greens). The study shows that there are considerably more men than women in the "No-Green" group.
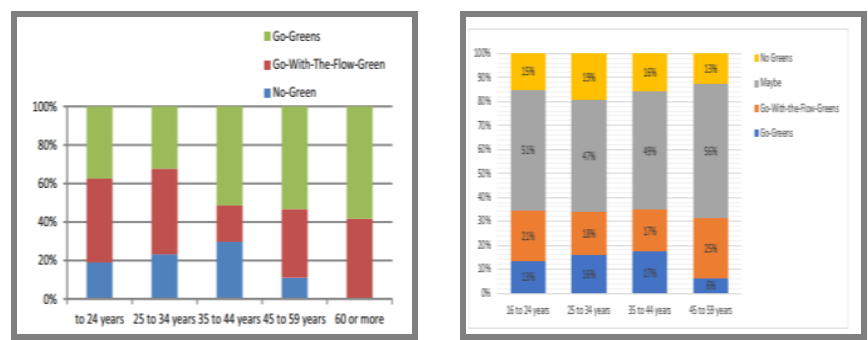

Figure 5. Ratio between Age Groups in different Consumers Segments

For Egypt, the results obtained for ratio between different age groups in different segments of consumers show that most chosen group is "Maybe" group, in every age group. Also, it could be noted that "Go Green" is decreasing with age. For Slovenia, only $11.1 \%$ of population above 44 can be defined as No-Greens. The ratio of GoGreens is increasing with age. It is also very interesting that we did not find any people above 60 years who would classify as No-Greens.

In Egypt, the respondents were asked about petrol and diesel prices, too. Ten percent of study participants were already seriously thinking about buying a car running on alternative fuels (e.g. biodiesel, bio alcohol, hydrogen and electricity). If gas prices increased by $30 \%, 60 \%$ of respondents would start thinking about buying a car which is powered by an alternative fuel. And If gas prices increased by $50 \%, 90 \%$ of respondents would start thinking about buying a car which is powered by an alternative fuel.

In Slovenia, the respondents were asked about petrol and diesel prices, too. Ten percent of study participants were already seriously thinking about buying a car running on alternative fuels (e.g. biodiesel, bio alcohol, hydrogen and electricity). If gas prices increased by 30\% (to EUR 1.96 per litre for petrol, and to EUR 1.80 EUR per litre for diesel), 58\% of respondents would start thinking about buying a car which is powered by an alternative fuel (30\% increase of petrol prices over several years is not an unlikely situation). And If gas prices increased by $40 \%, 80 \%$ of respondents would start thinking about buying a car which is powered by an alternative fuel.

\section{CONCLUSION}

Developed and developing countries needs to significantly accelerate growth toward higher efficiency, more de-carbonization, greater fuel diversity and lower emission of pollutants to manage the consequences of growing consumption and demand for commercial forms of energy. Egyptian and Slovenian respondents do not differ significantly regarding their perceptions in vehicle performance factors. With respect to financial cost, insurance cost, total price of the vehicle and fuel economy are the most important factors in both countries, besides, emissions of air pollutants are very important for Egyptian women, while Vehicle noise was observant in Slovenia.

Egyptian still not have the full awareness of LEV since it's a new concept for them however they have a positive attitude toward LEVs, even if they are not sure about buying one in the near future. On the other side in Slovenia, the biggest group is the Go-With-TheFlow-Greens with $39.2 \%$, while in Egypt a percentage of $19 \%$ is with that flow. Research demonstrate that there are considerably more men than women in the "No-Green" group, also it could be noted that "Go Green" is decreasing with age in Egypt unlike Slovenia it is 
increasing with age. The statistical testing revealed that when consumers are purchasing a car, they are more concerned with the total price of the car than in different taxes, more than $30 \%$ of Egyptian respondents would be seriously thinking about purchasing an electric car if prices decreased by $30 \%$, as well as more than one half $(59 \%)$ of Slovenian respondents would be seriously thinking about purchasing an electric car, if prices decreased by $30 \%$, Furthermore, the effect of different push and pull methods on different purchasers was also studied. In Egypt, the most influential measure is paying more VAT on higher emission cars. While in Slovenia, the most influential measure is 'Vehicle scrappage scheme'. Finally, the results illustrate the main influential factors between two different geographical areas and emphasize on the purchasing behaviour of consumers for LEV in future to help governments and manufacturers understand the attractive factors in different countries. Slovenian and Egyptian government must be aware that if they want to increase interest in purchasing LEVs, it should combine both pull and push factors, Push factor gives incentives to prospective users not to buy a car, provide rebates on VAT, vehicle registration fee and motor insurance premiums based on carbon emissions consumption and, at the same time pulls them to the low carbon modes public and non-motorized transport. Slovenian and Egyptian car industry should be aware that car drivers are more acquainted with information about fuel economy than information about a car's environmental influences (e.g. carbon emissions). Most people do not actually know the meaning of "grams of $\mathrm{CO}_{2}$ per $100 \mathrm{~km}$ " especially in Egypt and the amount of money they could save by buying a LEV.

Our research findings have few limitations. In order to obtain comparable data our methodology had to be wider and to enlarge the scale regarding population. Further limitations that we are aware that opinion and related preferences of people might change over time, and age of our respondents is an intervening variable.

\section{REFERENCES}

Atlam, B.A. and Rapiea, A.M. (2016), “Assessing the Future of Energy Security in Egypt", International Journal of Energy Economics and Policy, 6(4), 684-700.

Awad, M. (2018), Here Is Egypt's Plan to Halve its Air Pollution Rate by 2023, retrieved from http://cairoscene.com/Buzz/ministry-environment-reduce-pollution.

El-Dorghamy, A. (2014), "Fuel Economy and $\mathrm{CO}_{2}$ Emissions of Light-Duty Vehicles in Egypt", Centre for Environment and Development in the Arab Region and Europe, available at: https://www.globalfueleconomy.org/media/461049/me-and-wa_gfei_egypt_report_draft.pdf.

International Energy Agency (2017), "Global shifts in the energy system”, retrieved from https://www.iea.org

Knez, M., Jereb, B. and Obrecht, M. (2014), "Factors influencing the purchasing decisions of low emission cars: A study of Slovenia", Transportation Research Part D - Transport and Environment, https://doi.org/10.1016/J.TRD.2014.05.007.

Mostafa, A.R., Hegazi, A.H., El-Gayar, M.Sh. and Andersson, J.T. (2008), "Source characterization and the environmental impact of urban street dusts from Egypt based on hydrocarbon distributions", Fuel, 88, 95-104, https://doi.org/10.1016/j.fuel.2008.08.006.

Obrecht, M. and Denac, M. (2011), "Biogas - a sustainable energy source: new possibilities and measures for Slovenia", Journal of Energy Technology, 4(5), 1-10.

Obrecht, M. and Denac, M. (2018), "Forecast of Sustainable Energy Development in Slovenia", Journal of Energy Technology, 11(1), 57-68.

Slovenian Environment Agency (2019), “Air pollution”, retrieved from: http://www.arso.gov.si/en/soer/air_pollution.html.

Tawfik, F. (2018), "Cairo is world's second most polluted city: WHO”, retrieved from Egypt Independent: https://ww.egyptindependent.com/cairo-is-worlds-second-most-polluted-city-who/

*** (2018), “2018 Environmental Performance Index, Global metrics for the environment: Ranking country performance on high-priority environmental issues", Yale Center for Environmental Law \& Policy, Yale University, Center for International Earth Science Information Network, Columbia University. 